Fetal Diagnosis and Therapy

\title{
Treatment of Preterm Premature Rupture of Membranes with Oligo-/Anhydramnion Colonized by Multiresistant Bacteria with Continuous Amnioinfusion and Antibiotic Administrations through a Subcutaneously Implanted Intrauterine Port System: A Case Report
}

\author{
Michael Tchirikov ${ }^{\mathrm{a}}$ Zhaxybay Zhumadilov ${ }^{\mathrm{d}} \quad$ Andreas Suhartoyo Winarno $^{\mathrm{a}}$ \\ Roland Haase $^{\text {b Jörg Buchmann }}{ }^{c}$ \\ ${ }^{a}$ Department of Obstetrics and Prenatal Medicine, Center of Fetal Surgery, and b Department of Pediatrics and \\ Neonatology, University Hospital Halle (Saale), Martin Luther University Halle-Wittenberg, and ' Department of \\ Pathology, Martha-Maria Hospital, Halle (Saale), Germany; ${ }^{\mathrm{d} C e n t e r}$ for Life Science, National Laboratory Astana, \\ Nazarbayev University, Astana, Republic of Kazakhstan
}

\section{Established Facts}

- Preterm premature rupture of membranes (PPROM) with anhydramnion in the second trimester leads to pulmonary hypoplasia with a perinatal mortality of up to $80 \%$.

- After the rupture of the fetal membranes, the pathogenic bacteria infiltrate the amniotic cavity (funisitis and chorioamnionitis) and could infect the fetus. Intrauterine infection with a high concentration of inflammatory cytokines is related to an increase in the risk of developing periventricular leukomalacia and intraventricular hemorrhage in newborns.

- Expectant management, broad-spectrum antibiotics and antenatal corticosteroids are routinely used in PPROM with very limited success to prevent bacteremia, chorioamnionitis, funisitis and intra-amniotic infection syndrome. Numerous attempts sealing the rupture of the membrane including the use of collagen plugs, a slurry of platelets/fibrinogens, endoscopic closure of fetal membrane defects and also serial amnioinfusions have been unsuccessful.

\section{Novel Insights}

- We describe a novel use of continuous intra-amniotic lavage with an amniotic fluid-like solution combined with an intra-amniotic antibiotic administration via a subcutaneously implanted port system to flush out bacteria and inflammatory products from the amniotic cavity and prolog pregnancy of patients with PPROM and anhydramnion.

\section{KARGER}

E-Mail karger@karger.com www.karger.com/fdt
This article is licensed under the Creative Commons AttributionNonCommercial-NoDerivatives 4.0 International License (CC BYNC-ND) (http://www.karger.com/Services/OpenAccessLicense). Usage and distribution for commercial purposes as well as any distribution of modified material requires written permission.
Prof Michael Tchirikov, MD, PhD

Department of Obstetrics and Prenatal Medicine, Center of Fetal Surgery University Hospital Halle (Saale), Martin Luther University Halle-Wittenberg Ernst-Grube Strasse 40, DE-06120 Halle (Saale) (Germany) E-Mail michael.tchirikov@uk-halle.de 


\section{Key Words}

Amnioinfusion · Anhydramnion $\cdot$ Klebsiella $\cdot$ Preterm

premature rupture of membranes . Port

\begin{abstract}
Bacterial infection is one of the main causes of preterm premature rupture of membranes (PPROM) leading to preterm delivery, pulmonary hypoplasia, sepsis and joint deformities. Expectant management, broad-spectrum antibiotics and antenatal corticosteroids are routinely used in this condition with very limited success to prevent bacteremia, chorioamnionitis, funisitis and intra-amniotic infection syndrome. Here, we report a case in which we attempted to treat PPROM at $26^{+3}$ weeks of gestation with anhydramnion colonized by multiresistant Klebsiella. A perinatal port system was implanted subcutaneously at $28^{+0}$ weeks of gestation, enabling long-term continuous lavage of the amniotic cavity with a hypotonic aqueous composition similar to human amniotic fluid combined with intra-amniotic antibiotic application. The patient gave birth to a preterm female infant at $31^{+1}$ weeks without any signs of infection. The girl was discharged with a weight of $2,730 \mathrm{~g}$ in very good condition. In the followup examinations at 5 months and 1 year of age, there was no apparent neurological disturbance, developmental delay or Klebsiella colonization.

(c) 2015 The Author(s)

Published by S. Karger AG, Basel
\end{abstract}

\section{Introduction}

Preterm premature rupture of membranes (PPROM) with anhydramnion in the second trimester leads to pulmonary hypoplasia with a perinatal mortality of up to $80 \%$ $[1,2]$. Ureaplasma urealyticum, Sneathia species, Escherichia coli, Chlamydia trachomatis, Mycoplasma hominis, Enterococcus faecalis, and Gardnerella vaginalis are the common bacteria associated with PPROM $[2,3]$. The high concentration of inflammatory cytokines related to chorioamnionitis increases the risk of the development of periventricular leukomalacia and intraventricular hemorrhage in newborns [1-3]. Expectant management, broadspectrum antibiotics and antenatal corticosteroids are routinely used in this condition, with very limited success to prevent bacteremia, chorioamnionitis, funisitis and intra-amniotic infection syndrome [2]. Numerous attempts at sealing the rupture of the membrane including the use of collagen plugs, a slurry of platelets/fibrinogens, endoscopic closure of fetal membrane defects and also serial amnioinfusions have had limited success $[4,5]$.
The bacteria spread rapidly after the PPROM has occurred and colonize the surfaces of the amniotic membranes, the umbilical cord and the fetus (fig. 1). Low transplacental transfer of antibiotics is responsible for the moderate success of systemic antibiotic therapy $[6,7]$. Gomez et al. [8] stated that antibiotics could not eliminate the amniotic infection in $83 \%$ of PPROM cases. Romero et al. [3] described recently that upon clinical admission, $37.3 \%$ of the preterm PPROM patients delivered within $48 \mathrm{~h}$ of membrane rupture. Only $32.2 \%$ of all PPROM patients had a latent phase of more than 14 days.

The lavage effect of continued amnioinfusion could prevent the fetus and amniotic cavity from bacterial colonization, reduce the inflammatory response mediated by cytokines and protect the neonates from major complications such as pulmonary hypoplasia, sepsis, cerebral palsy and joint deformities [6]. We routinely used the intraamniotic antibiotic application for many weeks in a pregnant sheep model after open fetal surgery 1995-2005 at the Hamburg University without any adverse effects to the fetus [9]. In our opinion, the intra-amniotic antibiotic application related to the species of bacterial colonization of the amniotic cavity could additionally improve neonatal outcome. Here, we report a case in which we attempted to treat the PPROM with continuous lavage with a hypotonic aqueous composition similar to human amniotic fluid combined with intra-amniotic antibiotic infusion via a subcutaneously implanted port system.

\section{Case}

A 34-year-old second gravida, first para woman was referred to our Department of Obstetrics and Prenatal Medicine with PPROM at $26^{+3}$ weeks of gestation (WG). The patient did not have any history of smoking, alcohol, drug abuse, allergies and extragenital pathology. On admission, she complained of massive loss of amniotic fluid. The PPROM was confirmed by positive testing of the placental alpha microglobulin-1 (PAMG-1; AmniSure ${ }^{\circledR}$, Qiagen, France). No signs of amniotic infection syndrome such as maternal or fetal tachycardia, uterine contractions or significantly increased biochemical inflammation values (fig. 1) were observed. The results of the ultrasound examination were within the normal limit except for the deepest amniotic fluid pocket measuring $<1 \mathrm{~cm}$. The estimated fetal weight was $904 \mathrm{~g}$. The patient received a bolus tocolysis with fenoterol hydrobromide at a rate of $4 \mu \mathrm{g} / 3 \mathrm{~min}$ i.v. (Partusisten ${ }^{\circledR}$, Boehringer Ingelheim Pharma KG, Ingelheim, Germany) for $48 \mathrm{~h}$, until the prophylaxis of respiratory distress syndrome with a 2-day single course of $12 \mathrm{mg}$ betamethasone (Celestan ${ }^{\circledR}$, Essex Pharma, Munich, Germany) was accomplished (table 1). Cefuroxim 750 mg i.v. 3 times daily (Hikma Pharma GmbH, Graefelring, Germany) and metronidazol $500 \mathrm{mg}$ i.v. 4 times daily (Fresenius Kabi GmbH, Bad Homburg, Germany) were used instead of erythromycin because the adverse events were nausea and vomiting. The
72

Fetal Diagn Ther 2017;42:71-76

DOI: $10.1159 / 000438483$
Tchirikov/Zhumadilov/Winarno/Haase/ Buchmann 
Table 1. Timeline of antibiotic treatment and diagnostic tests

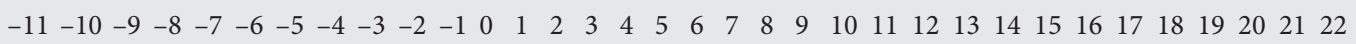

Treatment

Erythromycin (i.v.) $\quad+\quad+$

Cefuroxime (orally) +++++

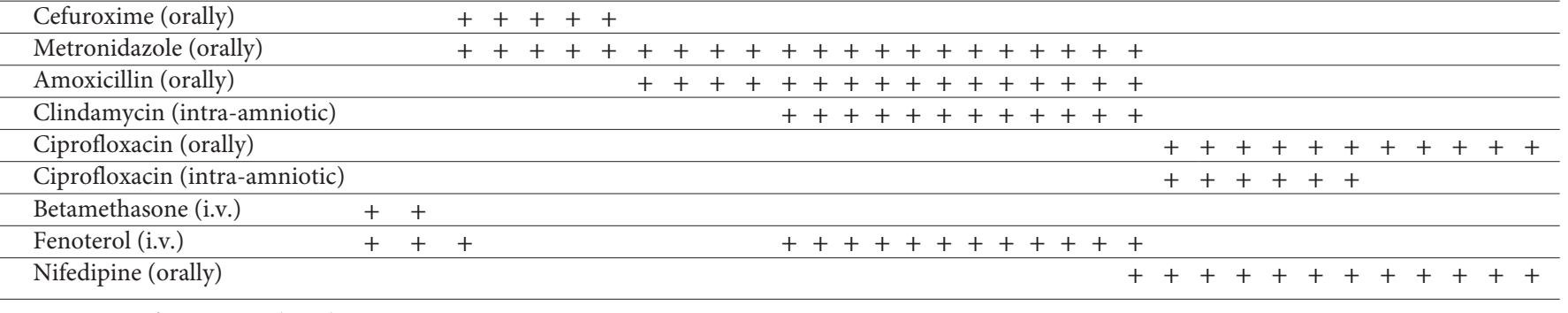

Diagnostic test from cervical swab

Enterococcus faecalis +

Klebsiella (ESBL) +

Enterobacter cloacae

complex (AmpC)

Klebsiella (3 MRGN)

$+$

Diagnostic test from tip of port catheter

Klebsiella (3 MRGN)

Sonography

Umbilical artery Doppler

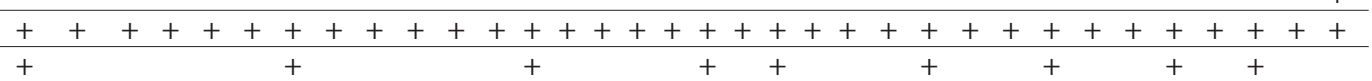

$\mathrm{ESBL}=$ Extended spectrum beta-lactamase; AmpC $=$ AmpC-type $\beta$-lactamase.

Fig. 1. Monitoring of CRP, interleukin-6 and procalcitonin after PPROM. Normal values for CRP $<5 \mathrm{mg} / \mathrm{l}$, interleukin- $6<6.4$ $\mathrm{pg} / \mathrm{ml}$, procalcitonin $<0.06 \mathrm{ng} / \mathrm{ml}$.

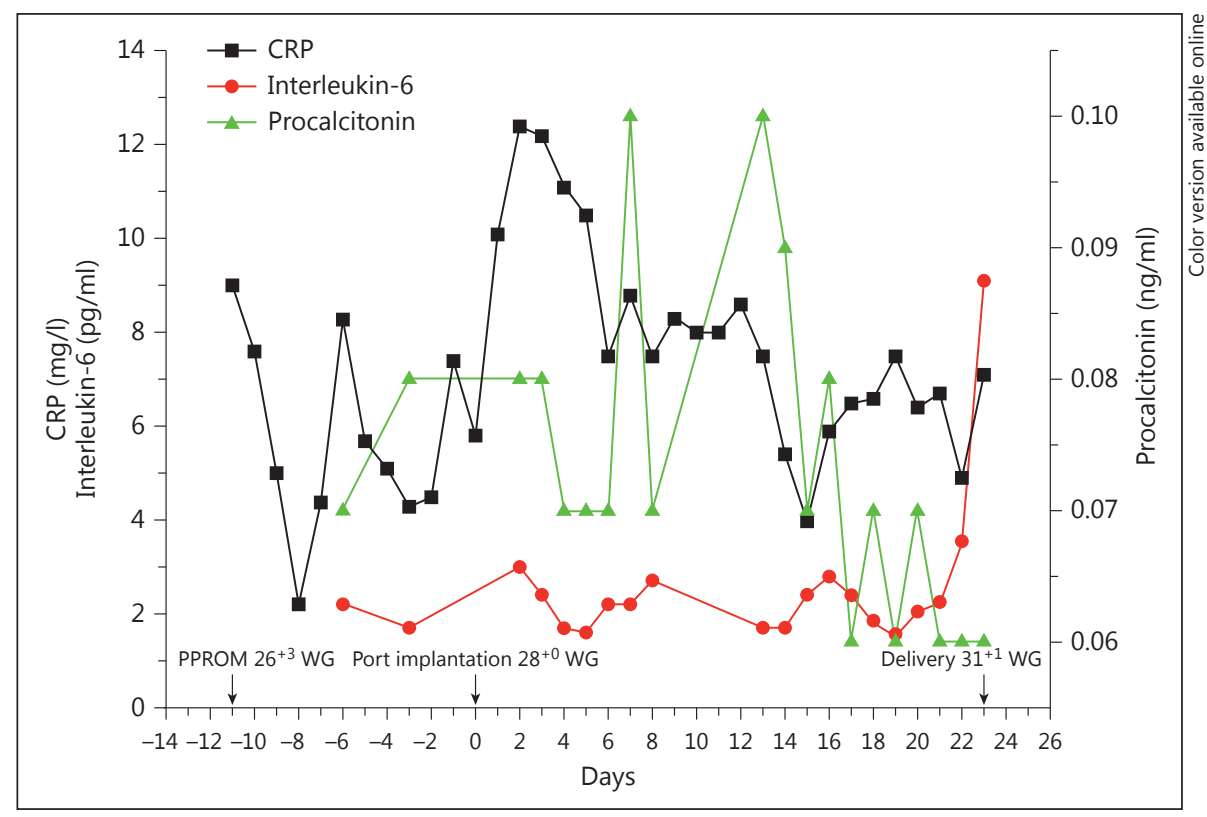

cervix was closed, and transabdominal sonography showed a cervical length of $30 \mathrm{~mm}$. The cervical canal bacterial swab test was performed weekly (table 1). The first result of the cervical canal bacterial swab test showed colonization by Enterococcus faecalis.

Appropriate counselling was provided including the risks and benefits of preterm birth for the fetus and mother and conservative management versus continuous amniotic infusion via a subcutaneously implanted port system with hypotonic amniotic fluid-like saline solution with reduced chloride content resembling the electrolyte concentration in human amniotic fluid at $100 \mathrm{ml} / \mathrm{h}(2,400$ $\mathrm{ml}$ daily) combined with intrauterine administration of antibiotics [10]. The port implantation was performed at $28^{+0} \mathrm{WG}$ (fig. 1) with 


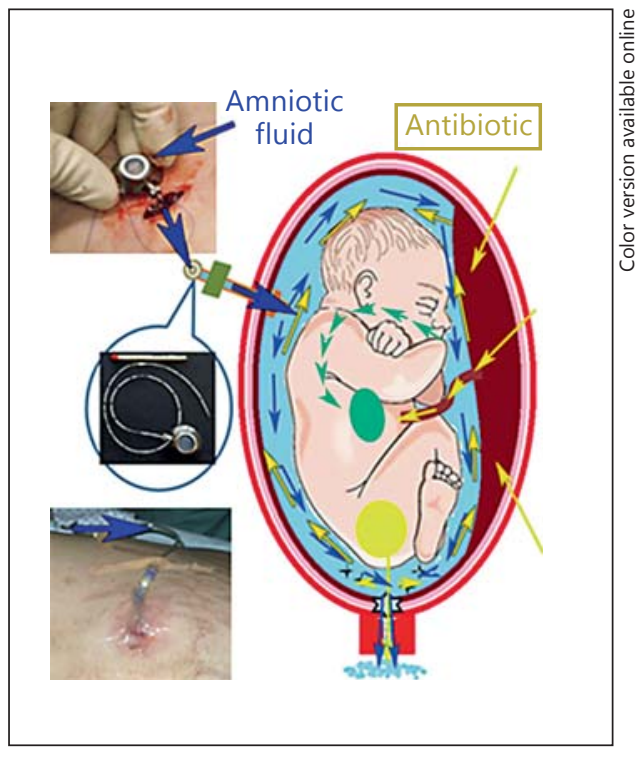

Fig. 2. Continuous amnioinfusion and antibiotic administration via subcutaneously implanted port. Blue color: hypoosmotic saline solution $(100 \mathrm{ml} / \mathrm{h}, 2,400 \mathrm{ml} /$ day $)$ with antibiotic used to flush out bacteria and inflammatory products from the amniotic cavity $(\downarrow)$. Yellow arrows: systemic antibiotic. Green arrows: the effect of fetal amniotic fluid swallowing. Upper left picture: the port system during the implantation. The connection to the infusion system port needle was covered by sterile foil (middle picture).

the permission of the Ethics Committee for individual treatment of the Martin Luther University Halle-Wittenberg (24012014) and written informed patient consent. The procedure involved intrauterine amnioinfusion of hypotonic aqueous composition relating to human amniotic fluid $(2,400 \mathrm{ml} /$ day $)$ and intrauterine administration of clindamycin $600 \mathrm{mg}$ (Fresenius Kabi, Bad Homburg, Germany).

Under local anesthesia with $10 \mathrm{ml}$ nonadrenalized $1 \%$ xylocaine, a small skin incision of about $3 \mathrm{~cm}$ was performed with a scalpel, and a subcutaneous pouch for the port capsule was prepared using a pair of scissors. An 18-gauge needle (Echotip ${ }^{\circledR}$ Disposable Trocar Needle, COOK Medical, Spencer, Ind., USA) was inserted into the amniotic cavity under ultrasound control (Philips EPIQ 7, Phillips Medical, Hamburg, Germany) through the prepared pouch. The port catheter (Tchirikov prenatal port system, PakuMed medical products GmbH, Essen, Germany) was inserted into the amnion, and the needle was removed. The port capsule was connected to the catheter and then inserted into the prepared pouch, where it was fixed with 3-0 Vicryl stitches to the subcutaneous fat tissue, and the skin was closed with Monocryl 4-0 (ETHICON, Cincinnati, Ohio, USA). Clindamycin $600 \mathrm{mg}$ (Fresenius Kabi) and a hypotonic solution related to human amniotic fluid ( Na $143.8 \mathrm{mmol} / \mathrm{l}$, K $3.9 \mathrm{mmol} / \mathrm{l}$, Ca $1.9 \mathrm{mmol} / \mathrm{l}, \mathrm{Mg} 0.57 \mathrm{mmol} / \mathrm{l}$, $\mathrm{Cl}^{-} 109.5 \mathrm{mmol} / \mathrm{l}, \mathrm{P} 3.3 \mathrm{mg} / \mathrm{dl}$, lactate $9.1 \mathrm{mmol} / \mathrm{l}$, citrate $66.5 \mathrm{mg} /$

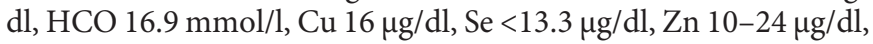
pH 8.35, osmolality <271; US009072755B2, University Pharmacy Halle UKH, Germany) were injected into the amniotic cavity through the port system (100 $\mathrm{ml} / \mathrm{h}$; fig. 2) [10].
At $29^{+6} \mathrm{WG}$, a vaginal swab culture isolated multiresistant Klebsiella pneumoniae with extended spectrum beta lactamase. Sensitive to the antibiogram, ciprofloxacin (Ciprobay, Bayer Vital, Germany) was administered for 10 days at $400 \mathrm{mg}$ /day through the port system into the amniotic cavity and $500 \mathrm{mg}$ per os.

The patient gave spontaneous birth to a female infant at $31^{+1}$ WG (birth weight 1,700g, APGAR score of 6/8/8, arterial pH 7.35, $\mathrm{BE}-1.8 \mathrm{mmol} / \mathrm{l})$. The port system was removed immediately after the delivery, and the catheter was sent for microbiological analysis. The port catheter was also positive for multiresistant K. pneumoniae.

The newborn was transferred to the neonatal intensive care unit for further diagnostic and therapeutic management. She required ventilator support for 1 day and continuous positive airway pressure for another day. At admission, interleukin- 6 and C-reactive protein (CRP) were within the normal range (CRP $<5 \mathrm{mg} / \mathrm{l}$, interleukin- $6<44.4 \mathrm{pg} / \mathrm{ml}$ ). The blood culture as well as the throat swab were sterile. However, the ear swab revealed multiresistant K. pneumoniae ( $3 \mathrm{MRGN}$, i.e. gram-negative bacteria with resistance against 3 of 4 defined antibiotic classes) [11]. The same multiresistant bacteria were found 1 week later in the rectal and throat swabs. However, the newborn did not require any antibiotic treatment because no clinical signs of neonatal inflection were displayed during the whole period of hospitalization. The neonate was discharged with a weight of 2,730 $\mathrm{g}$ at day 37 in a stable condition and without any signs of neurological deficiency. In the follow-up examinations at 5 months and 1 year of age, there was no apparent neurological disturbance, developmental delay or Klebsiella colonization.

On the second day after delivery, we received the report from the bacteriological laboratory indicating a 3 MRGN K. pneumoniae-positive rectal culture. On the third day after delivery (day 36 of admission), the patient was discharged from the hospital in a healthy condition without antibiotic treatment. In the follow-up examinations at 5 months and 1 year, no Klebsiella colonization could be detected. The histological examination of the amniotic membranes and the placenta showed no signs of chorioamnionitis (fig. 3). However, a thin leukocyte infiltration could be clearly identified in the decidua layer as a sign of inflammation response.

\section{Discussion}

The multidrug-resistant $K$. pneumoniae belong to a bacteria genus that has recently been more often isolated in a hospital setting [11]. In our case, the pregnancy was complicated by K. pneumoniae colonization. It is possible that the colonization of the amniotic membranes caused PPROM in our case. However, the hospital-associated infection must also be discussed [12, 13]. PPROM at $22^{+0}$ to $28^{+0} \mathrm{WG}$ complicates up to $7 \%$ of all pregnancies, is responsible for a third of all preterm births and is associated with severe perinatal morbidity and mortality [2]. If PPROM occurs in the second trimester followed by anhydramnion, the risk of pulmonary hypoplasia with extremely high neonatal mortality could increase up to $80 \%$. 


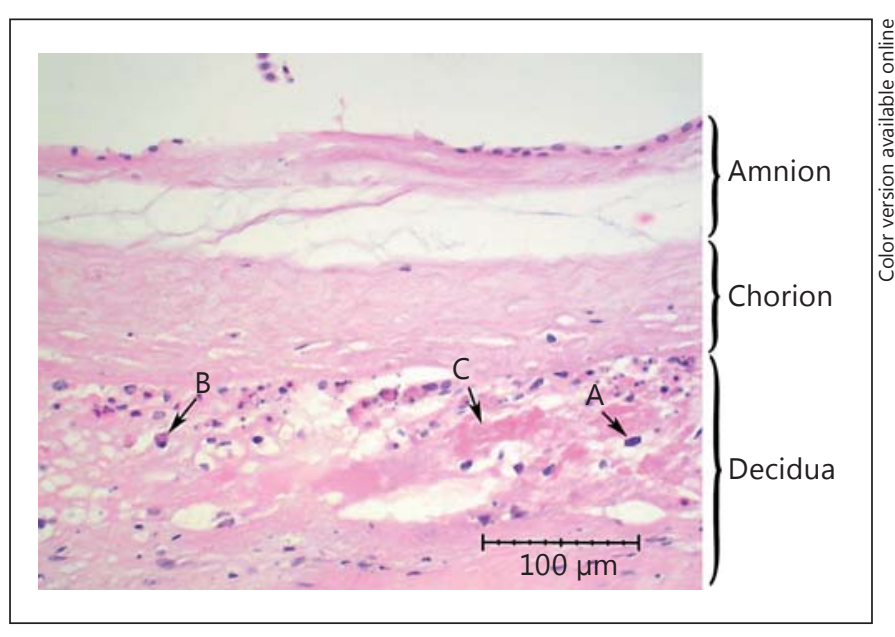

Fig. 3. Histologic examination of the chorioamniotic membranes after PPROM treatment with continuous intra-amniotic lavage. The amniotic and chorionic layers show no signs of inflammation. The decidua shows focal ribbon-like discrete inflammation, low number of neutrophils (A), sparse lymphocytes (B) and fibrin in between $(\mathrm{C})$.

Additionally, bacterial damage to fetal organs such as the lungs and brain lead to a worse outcome in preterm neonates. Romero et al. [3] described that every third patient with preterm PPROM delivered within $48 \mathrm{~h}$ of membrane rupture. However, $32.2 \%$ of all PPROM patients had a latent phase of more than 14 days.

The amniotic membranes and the umbilical cord do not have any capillary net, and thus, the antibiotics in the maternal circulation cannot target bacteria on colonized surfaces. Fetal urine containing cleared antibiotics is rapidly lost in the amniotic cavity through membrane rupture and without eliminating the bacterial infection (fig. 1). These pathophysiological pathways confirm that antibiotics cannot eliminate amniotic infection in PPROM [5].

Hatfield et al. [14], using newborn MRI, were able to demonstrate that chorioamnionitis was associated with long-term cognitive deficits related to decreased cortical thickness. Inflammatory responses in the fetal brain to intra-amnial infection (after PPROM) could also play a role in the high rate of neurological sequelae.

The use of transcervical application of amphotericin was described by Shalev et al. [15] in 1994 in a patient with Candida infection and preterm PPROM at 27 WG. After 7 days of treatment, the patient delivered spontaneously. Transcervical amnioinfusion is still used in clinical practice in the same countries only during the labor of PPROM patients with meconium-stained amniotic fluid [16].
In a recently published prospective randomized study, Roberts et al. [5] demonstrated that repetitive transabdominal amnioinfusions did not improve maternal and perinatal outcome in preterm PPROM patients. Fourteen neonates died in the amnioinfusion group versus 9 in the control group. Fetal skin in the second trimester is still very thin and permeable. This study used saline solutions with a higher sodium chloride level that could potentially change fetal programming. An accumulation of sodium and chloride might have disturbed the sodium potassium cell pumps and influenced the function of certain organs, e.g. cardiac, lung and brain. This could explain the high neonatal mortality rate after amnioinfusions in this study. Moreover, repetitive punctures could increase the risk of chorioamniotic separation, placental abruption and umbilical cord and fetus damage. Therefore, repetitive amnioinfusions have not been a reasonable treatment strategy until now.

We used continuous intra-amniotic lavage with a hypotonic aqueous composition with reduced chloride content related to human amniotic fluid combined with an intra-amniotic antibiotic administration to flush out bacteria and inflammatory products from the amniotic cavity and prolong pregnancy. It is likely that this strategy could improve neonatal outcome by protecting the neonate from the development of pulmonary hypoplasia, sepsis, intraventricular hemorrhage and joint deformities. In our case, the port catheter was positive for K. pneumoniae, as were the neonatal ear, rectal and throat swabs. The vaginal delivery may have spread the MRGN $K$. pneumoniae further in the newborn. A rectovaginal way of bacterial transmission is also possible in this case. Fortunately, 5 months later, no Klebsiella colonization could be isolated from the mother or child without antibiotic treatment after the delivery. Histologic examinations of amniotic and chorionic membranes showed no signs of chorioamnionitis. However, the described 'flush out' method is probably not able to stop the development of deciduitis resulting in activation of prostaglandin cascade and inducing preterm delivery in our case. We will trial this method again as appropriate and look forward to reading other efforts made in treating PPROM.

\section{Acknowledgements}

We thank Dr. Jessica Bell, University Halle-Wittenberg, Germany, who assisted in the manuscript preparation. 


\section{References}

1 Goldenberg RL, Culhane JF, Iams JD, Romero R: Epidemiology and causes of preterm birth. Lancet 2008;371:75-84.

2 Mercer BM: Preterm premature rupture of the membranes. Obstet Gynecol 2003;101: 178-193.

3 Romero R, Miranda J, Chaemsaithong P, Chaiworapongsa T, Kusanovic JP, Dong Z, Ahmed AI, Shaman M, Lannaman K, Yoon BH, Hassan SS, Kim CJ, Korzeniewski SJ, Yeo L, Kim YM: Sterile and microbial-associated intra-amniotic inflammation in preterm prelabor rupture of membranes. J Matern Fetal Neonatal Med 2014;29:1-16.

4 Young BK, Mackenzie AP, Roman AS, Stephenson CD, Minior V, Rebarber A, TimorTritsch I: Endoscopic closure of fetal membrane defects: comparing iatrogenic versus spontaneous rupture cases. J Matern Fetal Neonatal Med 2004;16:235-240.

5 Roberts D, Vause S, Martin W, Green P, Walkinshaw S, Bricker L, Beardsmore C, Shaw BN, McKay A, Skotny G, Williamson P, Alfirevic Z: Amnioinfusion in preterm premature rupture of membranes (AMIPROM): a randomised controlled trial of amnioinfusion versus expectant management in very early preterm premature rupture of membranes - a pilot study. Health Technol Assess 2014;18:131-135.
6 Park HS, Ahn BJ, Jun JK: Placental transfer of clarithromycin in human pregnancies with preterm premature rupture of membranes. J Perinat Med 2012;40:641-646.

7 Heikkinen T, Laine K, Neuvonen PJ, Ekblad $\mathrm{U}$ : The transplacental transfer of the macrolide antibiotics erythromycin, roxithromycin and azithromycin. BJOG 2000;107:770775 .

8 Gomez R, Romero R, Nien JK, Medina L, Carstens M, Kim YM, Espinoza J, Chaiworapongsa T, Gonzalez R, Iams JD, Rojas I: Antibiotic administration to patients with preterm premature rupture of membranes does not eradicate intra-amniotic infection. J Matern Fetal Neonatal Med 2007;20:167-173.

9 Tchirikov M, Kertschanska S, Schröder HJ: Obstruction of ductus venosus stimulates cell proliferation in fetal organs. Placenta 2001;22: 24-31.

10 Tchirikov M, Bapayeva G, Zhumadilov ZS, Dridi Y, Harnish R, Herrmann A: Treatment of PPROM with anhydramnion in humans: first experience with different amniotic fluid subtitutes for continuous amnioinfusion through a subcutaneously implanted port system. J Perinat Med 2013;41:657-663.

11 KRINKO: Ergänzende Empfehlung zur 'Prävention nosokomialer Infektionen bei neonatologischen Intensivpatienten mit ei- nem Geburtsgewicht unter 1,500 g'. Epidemiol Bull 2012;2:13-15.

12 Bernaschi P, Del Chierico F, Petrucca A, et al: Microbial tracking of multidrug-resistant Klebsiella pneumoniae isolates in a pediatric hospital setting. Int J Immunopathol Pharmacol 2013;26:463-472.

13 Haller S, Eller Ch, Hermes J, et al: What caused the outbreak of ESBL-producing Klebsiella pneumoniae in a neonatal intensive care unit, Germany 2009 to 2012? Reconstructing transmission with epidemiological analysis and whole-genome sequencing. BMJ Open 2015;5:e007397.

14 Hatfield T, Wing DA, Buss C, Head K, Muftuler LT, Davis EP: Magnetic resonance imaging demonstrates long-term changes in brain structure in children born preterm and exposed to chorioamnionitis. Am J Obstet Gynecol 2011;205:384.e1-e8.

15 Shalev E, Battino S, Romano S, Blondhaim O, Ben-Ami M: Intraamniotic infection with Candida albicans successfully treated with transcervical amnioinfusion of amphotericin. Am J Obstet Gynecol 1994;170:1271-1272.

16 Puertas A, Tirado P, Pérez I, López MS, Montoya F, Cañizares JM, Miranda JA: Transcervical intrapartum amnioinfusion for preterm premature rupture of the membranes. Eur J Obstet Gynecol Reprod Biol 2007;131:40-44. 